PNL-SA-22157

\title{
AEDOT TECHNOLOGY
}

D. L. Shankle

March 1993

Handout

Prepared for the U.S. Department of Energy under Contract DE-ACO6-76RLO 1830

\section{MASTER} DISTRIBUTION OF THIS DOCUMENT IS UNLIMITED

Pacific Northwest Laboratory Richland, Washington 99352

\author{
$f^{2}$ \\ RECEIVED \\ MAY 111993 \\ OSTI
}




\section{AEDOT TECHNOLOGY}

Most commercial buildings designed today will use more energy and cost more to operate and maintain than necessary. If energy performance were considered early in building design, $30 \%$ to $60 \%$ of the energy now used in new commercial buildings could be saved cost-effectively. However, most building design teams do not adequately consider the energy impacts of design decisions to achieve these savings; the tools for doing so simply do not yet exist.

Computer technology can help design teams consider energy performance as an integral part of the design process. This technology could enable designers to produce much more energy-efficient buildings without increasing the costs of building design.

Recognizing this, the U.S. Department of Energy (DOE) has initiated the Advanced Energy Design and Operation Technologies (AEDOT) project, led by Pacific Northwest Laboratory (PNL) ${ }^{a}$. The aim of the project is to develop advanced computer-based technologies that will help designers take advantage of these potentially large energy savings.

The success of the AEDOT project depends largely on the ability to develop energy design-support tools that can be integrated into comprehensive building design environments so that all parts of the design process will be supported. Energy, just one consideration among many in building design, must be considered in a context that includes visual, acoustic, and structural aspects; accessibility; thermal comfort; indoor air quality; cost; and other factors associated with the quality, acceptability, and performance of a building. Advanced computer-aided design support environments will need to integrate tools from many different domains and provide access to the vast amounts of data that designers need to apply these tools and to make informed design decisions.

\section{AEDOT Prototype I}

The AEDOT Prototype 1, which made its public debut at the $A / E / C$ Systems ' 92 trade show in Dallas on June 8-11, 1992, illustrates how advanced energy tools can be integrated into the CAD environment. Prototype 1 was developed in a collaborative effort led by PNL, including developers from California Polytechnic State University (Cal Poly), University of Oregon, and Lawrence Berkeley Laboratory (LBL). The prototype includes three advanced energy tools-- the Building Massing Tool, the Daylighting Tool, and the Energy Standards Tool--that have been implemented as components of a software framework called the Intelligent Computer-Aided Design System (ICADS).

ICADS, which was developed by Cal Poly with support from Accugraph, IBM, and Hewlett Packard, uses Accugraph CAD software as the primary user interface. It contains a commercial CAD drawing package, a geometry interpreter, several databases, and several intelligent design tools (IDTs). The IDTs, which are linked through a blackboard, provide information to the designer about such

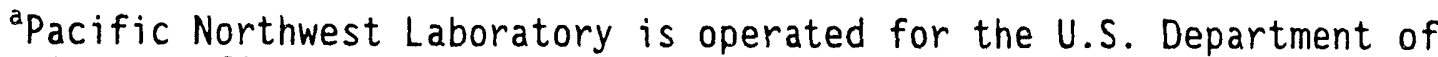
Energy by Battelle Memorial Institute under Contract DE-ACO6-76RLO 1830.
} 
topics as the structural, thermal, acoustic, and cost impact of each addition or modification that a designer makes to a design.

A designer interacts with the prototype by developing the floor plan for a building design on the computer screen using the CAD drawing package, which is a version of Accugraph's commercially available MountainTop CAD package that has been customized for use in ICADS. As architectural elements (e.g., rooms, doors, windows) are drawn on the screen, they are identified and transformed by the geometry interpreter into corresponding data objects that are then posted to the ICADS blackboard. Once these objects appear on the blackboard, they immediately become available to the IDTs, including the advanced energy tools, for analysis and evaluation.

\section{Building Massing Tool}

The University of Oregon developed the Building Massing Tool, which allows the designer to see how energy performance varies with building geometry. The tool compares the architect's design to designs stored in its database to identify alternative configurations that have better energy performance. The tool looks at such factors as plan configuration, insulation level, glazing distribution, and construction type.

\section{Daylighting Tool}

Lawrence Berkeley Laboratory (LBL) developed the Daylighting Tool, which computes and graphically displays daylight workplane illuminance throughout a room at any time of year, and determines associated energy savings for electric lighting and glare. The daylighting tool uses algorithms that LBL developed for its DOE-2 building energy simulation software, but with greatiy enhanced graphic display.

\section{Energy Standards Tool}

PNL developed the Energy Standards Tool to automatically check compliance with requirements for lighting power, lighting controls, ballast efficiency, and fenestration set in ASHRAE/IES Standard 90.1. The tool informs the designer of instances of noncompliance, provides explanations for the noncompliance condition, and recommends design changes to the user that will bring the design closer to compliance.

\section{Importance of The AEDOT Prototype I}

The AEDOT Prototype 1 demonstrates how advanced energy tools can be integrated with a CAD capability. By doing this, the prototype illustrates the following important concepts:

- Energy tools can be linked to the designing/drawing activities. This automatic data link frees the designer from the need to prepare separate input data for energy tools, saving time and allowing the energy performance evaluations to proceed concurrently as part of the design process.

- Energy tools in Prototype 1 work in the background and they self actuate (i.e., the designer need not interrupt design thinking to use these tools). The tools operate whenever they have sufficient information to activate, and they present detailed information only when the designer asks for it. 
- Energy tools operate concurrently, allowing multiple "views" of the problem to be explored in parallel. Concurrent operation provides the basis for inter-tool negotiation and conflict resolution.

- The energy tools provide customized assistance to the architect or engineer during the design process. Suggestions and recommendations made by the tools are tailored specifically to the building that is being designed, not to some generic building type.

\section{Future Directions}

Although the AEDOT project will rely on state-of-the-art technologies, a major goal of the project is to make the energy design tools so easy to use that they add no extra time to the design process. In fact, they may actualiy reduce the time requirements and costs.

The AEDOT team foresees the use of AEDOT-developed software to support decision-making throughout a building's life. For example, computers at the construction site will be used to make sure the designer's energy efficiency goals are taken into account when changes are made during construction. The project also plans to contribute to the development of systems that improve the operation and management of completed buildings to increase their energy efficiency.

The next step in AEDOT is to build a set of complete energy design tools, to resolve some fundamental technical problems identified during development of Prototype 1, and to work collaboratively with industry to begin moving these capabilities and energy tools into software systems used by designers.

\section{DISCLAIMER}

prepared as an account of work sponsored by an agency of the United States This report was prepared as an account of work sponsored by agency thereof, nor any of their Government. Neither the United States Government nor any agency thereof, nobility or responsiemployees, makes any warranty, express or implied, or assumes any legal liabilitys, product, or bility for the accuracy, completeness, or usefulness of any information, apparatus, product Referprocess disclosed, or represents that its use would not infringe priva by trade name, trademark, ence herein to any specific commercial product, process, or imply its endorsement, recommanufacturer, or otherwise does not necessarily constitu or any agency thereof. The views mendation, or favoring by the United States Government or any agency therect those of the

and opinions of authors expressed herein do not
United States Government or any agency thereof. 

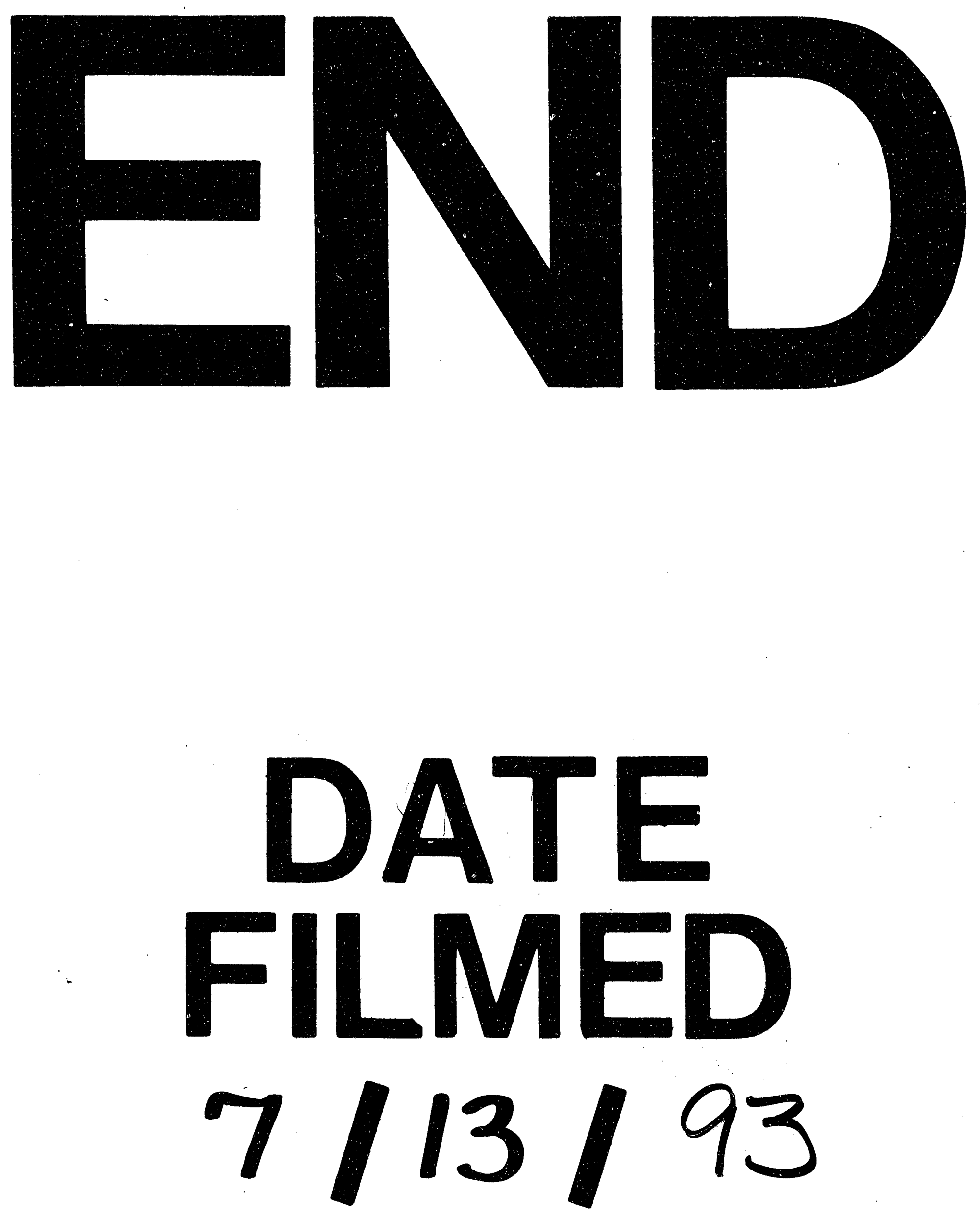
• 